\title{
Discurso de Eduardo Valencia-Ospina
}

\author{
Presidente de la Comisión de Derecho Internacional en su septuagésimo \\ período de sesiones
}

(Spanish original)

Constituye un gran honor para mí, en nombre de la Comisión de Derecho Internacional, dar la bienvenida a todos Ustedes a esta sesión solemne - la segunda en conmemoración del septuagésimo aniversario de la Comisión, después de la realizada en Mayo de este año en la Sede de las Naciones Unidas en Nueva York.

Permítanme expresar el agradecimiento de la Comisión a nuestros invitados de honor por su presencia aquí en el día de hoy. Deseo reconocer en el podio: al Sr. Miguel de Serpa Soares, Asesor Jurídico de las Naciones Unidas, en representación del Secretario General; a la Sra. Corinne Cicéron Bühler, Directora General de Derecho Internacional del Departamento Federal de Asuntos Exteriores de Suiza, el Estado anfitrión de la Comisión; a la Sra. Kate Gilmore, Alta Comisionada Adjunta de las Naciones Unidas para los Derechos Humanos; y a Su Excelencia el Juez Abdulqawi Yusuf, Presidente de la Corte Internacional de Justicia, quien dictará la Conferencia magistral con la que concluirá esta solemne jornada.

Es también muy grato para la Comisión saludar entre la concurrencia a varios otros jueces de la Corte Internacional de Justicia, representantes de Estados Miembros y de agencias Especializadas y otros Organismos Internacionales y asesores jurídicos de Cancillerías, así como a eminentes académicos y profesionales del Derecho, incluyendo a antiguos miembros de la Comisión.

La conmemoración del septuagésimo aniversario de la Comisión de Derecho Internacional es una celebración del derecho internacional.

$\mathrm{Al}$ asumir la primera presidencia de la Comisión en Lake Success, Nueva York, el 12 de abril de 1949, el Sr. Manley Hudson, se refirió a la Historia como el motor de las actividades de la Comisión. De hecho, consideró que era imposible para un jurista "olvidar las lecciones de la historia" ("to forget the lessons of history"). ${ }^{1}$ La Comisión -continuó él- debería tomar en consideración los muchos logros graduales que la precedieron, pero reconocer al mismo

1 CDI, 'Actas resumidas y documentos de la primera sesión, incluido el reporte de la Comisión a la Asamblea General' [1949] Anuario de la CDI 1949, 10. 
tiempo el perpetuo movimiento entre el presente y el futuro, para así evitar convertirse en una mera esclava del pasado.

Siendo el año el de 1949, sus palabras fueron una clara referencia a los desarrollos históricos más recientes. Naciente, como empezaba a serlo de entre los escombros dejados por el horror y aflicción de la Segunda Guerra Mundial, la comunidad internacional de naciones que, abatidas por dos grandes guerras que se sucedieran en un breve período, habían fracasado en el logro de su promesa de una paz duradera y estable, emprendió el proceso de reconstruir la promesa incumplida, a través del mantenimiento y avance del derecho internacional. Mirar al pasado era, por tanto, una forma de crear el futuro. El lema de nuestros eventos conmemorativos, "estableciendo un balance para el futuro”, refleja ese deseo muy humano de introspección y prospección: aprender las lecciones del pasado para perfeccionar el futuro.

Dadas las circunstancias imperantes en el momento de su creación, la Comisión fue establecida precisamente para transitar con cuidado por este sendero entre el pasado y el futuro, iniciando estudios y formulando recomendaciones para promover el desarrollo progresivo del derecho internacional y su codificación, que es la misión que le asignara la Asamblea General con miras a la aplicación del Artículo 13, párrafo 1, de la Carta de las Naciones Unidas.

Personalmente he tenido el privilegio de observar y participar de cerca en ese andar de la Comisión desde varias aventajadas posiciones tanto internas como externas: formando parte de su Secretaría en los años 6o y 70; en mi condición de Secretario Adjunto y Secretario de la Corte Internacional de Justicia en los años 80 y 9o; y, desde 2006, como miembro, luego Relator Especial, y ahora Presidente de la propia Comisión. En cada una de esas etapas he podido constatar a todo momento la continua relevancia en el transcurso del tiempo, de todos los aspectos del trabajo de la Comisión para nuestra tarea profesional de juristas internacionales. En este sentido, me refiero no sólo a los muchos tratados multilaterales que surgieron como resultado de las labores de la Comisión, sino también a otros diversos elementos que entran en juego en el proceso de desarrollo progresivo y codificación, a los que hacemos constante referencia en nuestras actividades cuotidianas. En efecto, es posible tomar en consideración la extensa práctica de los Estados recopilada por la Comisión y su Secretaría a lo largo de los años; las observaciones y comentarios expresados por los Estados oralmente o por escrito; la variedad y la pluralidad de los puntos de vista emitidos por los miembros de la Comisión durante los debates. Con frecuencia, repasamos los esfuerzos realizados en el pasado, en particular las opiniones de los miembros de la Comisión en las décadas a partir de los años cincuenta, a fin de afianzarnos en la búsqueda de las mejores soluciones para el futuro dentro del proceso de desarrollo progresivo del derecho internacional y su codificación. 
Un tal proceso implica inherentemente períodos de una cierta extensión, a diferencia de lo que sucede cuando se trata de acordar un "derecho instantáneo". Y posee un significado que connota además una concepción unitaria del desarrollo progresivo del derecho internacional y su codificación. Como es bien sabido, el artículo 15 del Estatuto de la Comisión establece una distinción, "por comodidad", entre ambos conceptos. En la práctica, sin embargo, el trabajo de la Comisión sobre un determinado tema involucra al tiempo ciertos aspectos de desarrollo progresivo así como de codificación, y el equilibrio entre ambos varía dependiendo del tema de que se trate. Durante el Congreso organizado en el marco del Decenio de las Naciones Unidas para el Derecho Internacional en 1995, tuve la oportunidad de señalar que la codificación y el desarrollo progresivo, a pesar de estar formalmente diferenciados en el Estatuto, en realidad se han fusionado en un concepto más amplio de "codificación", que ya no se ve sólo como la mera transposición de "ley no escrita" a "ley escrita" (lo que podría denominarse codificación "clásica"). ${ }^{2}$ El futuro, entonces, resulta estar siempre plegado al pasado. A su vez, esta concepción más amplia de la codificación está estrechamente vinculada a la observación de que la forma final del trabajo de la Comisión, ya sea éste plasmado en artículos independientes destinados a traducirse en una convención, o directrices, conclusiones, principios o simplemente en un informe, sea tal vez de menor trascendencia para el futuro que el complejo proceso de desarrollo progresivo y codificación considerado en sí mismo.

Si bien tradicionalmente se consideró que el objetivo final de todos los esfuerzos de la Comisión sobre un determinado tema debería ser la elaboración de un instrumento internacional que consagrara en forma vinculante los resultados de su trabajo, la experiencia más reciente ha demostrado que esto no necesariamente es así en todos los casos. Algunos de los textos más autoritativos e invocados con mayor frecuencia que hayan surgido de la labor de la Comisión, redactados en forma de artículos, no se han convertido hasta el momento en tratados multilaterales. La travesía es pues tan importante como el destino; un ejercicio en perpetuo movimiento, el pasado informando el presente para hacer realidad un mañana mejor.

La anterior constatación fáctica no debe dar lugar a interpretaciones erróneas: el hecho de que se pueda dar una de las varias formas posibles a un proyecto definitivo de codificación, no significa que los tratados hayan llegado a convertirse en instrumentos obsoletos. La realización del anhelado "mañana

2 Naciones Unidas (ed), International law as a language for international relations/Le droit international comme langage des relations internationales/El derecho internacional como lenguaje de las relaciones internacionales (Kluwer Law International 1996) 523. 
mejor" requiere con frecuencia la fuerza de la concertación internacional en la elaboración de tratados para expresar todo su potencial: puede ser necesario establecer instituciones, o que las leyes nacionales sean armonizadas gracias a normas comunes vinculantes. A este respecto, es altamente significativo que, recientemente, la Comisión haya recomendado explícitamente por consenso a la Asamblea General que el último proyecto definitivo a ella sometido sea convertido en una convención multilateral. Tal fue en 2016 el caso del relativo al tema sobre el que tuve el honor de ser Relator Especial: la "Protección de las personas en caso de desastre"; 3 y se espera que sea el caso también el año próximo en relación con el proyecto definitivo a adoptar sobre los "Crímenes de lesa humanidad". Ambos proyectos tienen el potencial de conducir a tratados que demuestren ser históricamente trascendentales para la cimentación del ansiado futuro jurídico internacional.

La Historia, por supuesto, es creada por seres humanos, no por entidades abstractas. El papel autoritativo atribuido a la Comisión a lo largo del tiempo y la relevancia de sus resultados, incluso cuando éstos no se transforman en un tratado multilateral, reposa en última instancia en el reconocimiento generalmente extendido hacia las grandes mentes de juristas, gigantes intelectuales, de todo el orbe que han recorrido los pasillos del Palais des Nations en ejercicio de su noble oficio. Esta es la dimensión humana de la Comisión. Podemos referirnos a ellos como a las muchas voces que han articulado el trabajo de la Comisión con el transcurso del tiempo: a pesar de (o debido a) su pluralidad, diversidad y, a veces, divergencia, todos ellos han contribuido en alguna medida a crear la voz colegiada de la Comisión. Los métodos de trabajo de la Comisión están diseñados para que el producto final sea siempre plural y mayor que la suma de sus partes: es el destilado, la síntesis de las opiniones de muchas mentes jurídicas que trabajan por un objetivo común. La interacción de una balanceada representación regional, aunque no de género todavía, y de diferentes tradiciones y sistemas jurídicos en la composición de la Comisión es esencial a este respecto, como lo es también la independencia de los individuos que son miembros de la Comisión frente a los Gobiernos. En este esfuerzo colectivo -un punto que no debe olvidarse- también ha sido esencial, desde el principio, el destacado papel que ha sido reservado a la Secretaría de la Comisión, cuyos estudios preparatorios y asistencia jurídica sustantiva, que forman parte de los métodos de trabajo de la Comisión, son cruciales para su buen funcionamiento.

3 CDI, 'Informe de la Comisión de Derecho Internacional sobre el trabajo de la Comisión en su sexagésima octava sesión' (2016) Documento de Naciones Unidas No. A/71/10, 13. 
Excepto en un par de ocasiones, la más reciente cuando sesionamos en la Sede de las Naciones Unidas en Nueva York por cinco semanas, Ginebra siempre ha sido el hogar de la Comisión. Su trabajo sustancial se ha desarrollado aquí. Los antiguos miembros, así como los miembros actuales, guardan cálidos recuerdos del Palais y de la ciudad y sus alrededores. La Comisión está profundamente reconocida al Gobierno del Estado anfitrión por el constante y generoso apoyo que le ha brindado a lo largo de su historia. Y la Comisión manifiesta también su agradecimiento a la Oficina de las Naciones Unidas en Ginebra, en especial su Biblioteca y Servicios de Conferencias, por su continua cooperación y eficaz atención, indispensables para el buen funcionamiento de las reuniones anuales de la Comisión. 